\title{
IgG levels in Human Papillomavirus Infection Associated with Clinical Stage of Head and Neck Squamous Cell Carcinoma
}

\author{
Yussy Afriani Dewi, Agung Dinasti Permana, Fanny Yudhiono \\ Department of Otorhinolaryngology-Head and Neck Surgery Faculty of Medicine Universitas \\ Padjadjaran/Dr. Hasan Sadikin General Hospital Bandung, Indonesia
}

\section{Abstract}

Background: Head and neck squamous cell carcinoma (HNSCC) is an invasive neoplasm of epithelial tissue in the head and neck and one of the etiologies of HNSCC is human papillomavirus (HPV) which may be associated with the clinical stage of HNSCC. HPV infection in squamous cell epithelium produces specific IgG antibodies against HPV. IgG titer of HPV can help identify patients who are at risk for HPVrelated cancers. This study aimed to explore the association between IgG titer of HPV with the clinical stages of HNSCC.

Methods: The design of this study was analytic cross sectional, conducted at the Outpatient Clinic of Otorhinolaryngology-Head and Neck Surgery, Division of Oncology, Dr. Hasan Sadikin General Hospital Bandung period September-December 2017. Patients with HNSCC were recruited, and history was taken. Furthermore, histopathologic examination and HPV IgG serology examination were performed using the ELISA method. The HPV IgG levels were compared by stage and data were analyzed using the Shapiro Wilks test and Unpaired T test.

Results: The HPV IgG was high in $75 \%(n=21)$ of HNSCC patients in the advanced stage and low in $25 \%$ $(n=7)$ of patients in the early stage. There was a significant relationship between HPV IgG titer and early and advanced stage of HNSCC ( $\mathrm{p}=0.001)$.

Conclusions: The HPV IgG titer is related to the clinical stage of HNSCC indicating that the higher the HPV IgG level, the more advanced the clinical stage. Further study is needed to explore HPV IgG levels as a prognostic marker in HNSCC.

Keywords: HNSCC stage, HPV IgG, squamous cell carcinoma

\section{Introduction}

Head and neck squamous cell carcinoma (HNSCC) is a cancer that arises from the mucosal epithelium of the upper aerodigestive tract. ${ }^{1}$ Head and neck squamous cell carcinoma is an aggressive, life-threatening cancer associated with a high mortality rates. The incidence of HNSCC is about $90 \%$ of all head and neck cancers and is the sixth in the world. Head and neck squamous cell carcinoma is the seventh leading cause of death and is increasing in developing countries by about 500,000 cases per year. ${ }^{2,3}$ The prevalence of head and neck cancer at Dr. Hasan Sadikin General Hospital Bandung for the 2010-2014 period was $31.2 \%{ }^{4}$

Human papillomavirus (HPV) is one of the factors that cause the growth of abnormal cells. The HPV infection causes interactions between oncoprotein E6 and p53 in cell cycle control settings, apoptosis, and DNA repair. Disruption of TP53 leads to cancer proliferation and progression. The p53 and p73 proteins have similar domain structures, indicating analogous biological activity and contribute to the increased risk of HPV-16 in HNSCC. P53 instability leads to p21 transcription, deregulation of DNA repair, and inhibition of p53 proapoptotic function. Decreased p21, degradation of DNA deregulation, and inhibition of proapoptotic function may result in proliferation; whereas the decreased function of p53 proapoptosis can directly increase progressivity. Furthermore, the increased proliferation of epithelial cells with

Correspondence: Yussy Afriani Dewi, Department of Otorhinolaryngology-Head and Neck Surgery, Faculty of Medicine Universitas Padjadjaran/Dr. Hasan Sadikin General Hospital , Jalan Pasteur 38, Bandung Indonesia, E-mail: yussy.afriani@unpad.ac.id 
high levels of HPV IgG causes progressivity of tumor. $^{5}$

The increased risk of HNSCC is related to HPV-16 seropositivity examined using IgG ELISA. HPV-16 is also a risk factor associated with Oropharyngeal Squamous Cell Carcinoma (OPSCC). Moreover, HPV has also been linked to the pathogenesis of oral cancer. The death rate of head and neck squamous cell carcinoma is very high, associated with the stage of the tumor when patients first come to the hospital. ${ }^{6,7}$ This research was aimed to explore the correlation between IgG HPV titer and the clinical stage of HNSCC

\section{Methods}

This study was a cross-sectional analytic study at the OutpatientClinic ofOtorhinolaryngologyHead and Neck Surgery, Division of Oncology, Dr. Hasan Sadikin General Hospital Bandung period September-December 2017. HNSCC patients were collected before recruitment. Informed consent was obtained from all individual participants included in the study.

Inclusion criteria were patients with head and neck tumors in the early and advanced stages with histopathological results of squamous cell carcinoma (SCC). Furthermore, HNSCC patients were included when they had not received radiation therapy, chemotherapy, or chemoirradiation. Exclusion criteria were patients with residual or recurrence of SCC, multiple carcinomas, patients who had received radiotherapy. The study was approved by the Research Ethics Committee of Dr. Hasan Sadikin Hospital Bandung, Indonesia No. LB.04.01/A05/EC/304/X/2017.

Clinical stages were designated by early- stage (I-II) HNSCC, and advanced stage (III-IV) based on the 2017 American Joint Committee on Cancer (AJCC). The locations of HNSCC were the oropharynx, paranasal sinuses, nasopharynx, oral cavity, and larynx. Histopathology of SCC was classified based on the results of the biopsy showing squamous differentiation microscopically. The HPV IgG levels were obtained from blood serum and examined by ELISA method using monoclonal antibodies of with quantitative serum levels of $156-10.000 \mathrm{U} / \mathrm{mL}$. Statistical analysis was performed using the Mann Whitney test and the Fisher's Exact correlation test.

\section{Results}

In total, 28 patients with HNSCC were included, the most of patients were male (19 of 28) with a mean age of $53.78 \pm 8.385$ years (range 3370 years). There was no relationship between gender $(p=0.646)$ or age $(p=0.972)$ with the clinical stage of HNSCC (Table 1).

Based on the location of the tumor, the most prevalent site was in the larynx $(n=17)$ whereas advanced stage was the most prevalent site as shown in Table 2. Interestingly, there was a significant relationship between the HPV IgG levels and the clinical stage of HNSCC $(\mathrm{p}=0.001)$. The HPV IgG levels in the advanced stage $(4,708 \pm 1,386)$ were significantly higher than in the early-stage $(2,344 \pm 1,255)$ as shown in Table 3.

\section{Discussion}

Head and neck cancers are all cancers that originate in the upper aerodigestive tract, including the sinonasal tract, oral cavity,

Table 1 Characteristics of Patients with Head and Neck Squamous Cell Carcinoma from Dr. Hasan Sadikin General Hospital in 2019

\begin{tabular}{|c|c|c|c|c|}
\hline \multirow{2}{*}{ Characteristics } & Early Stage & Advanced Stage & \multirow{2}{*}{ Total } & \multirow{2}{*}{ P-value } \\
\hline & $n=7$ & $n=21$ & & \\
\hline Sex & & & & $* 0.646$ \\
\hline Male & 4 & 15 & 19 & \\
\hline Female & 3 & 6 & 9 & \\
\hline Age (year) & & & & $* * 0.927$ \\
\hline $31-40$ & 0 & 2 & 2 & \\
\hline $41-50$ & 3 & 2 & 5 & \\
\hline$>50$ & 4 & 17 & 21 & \\
\hline Mean \pm SD (Age) & $52.42 \pm 6.267$ & $54.23 \pm 9.071$ & $53.78 \pm 8.385$ & $* * 0.630$ \\
\hline Median (Age) & 51.000 & 55.000 & 55.000 & \\
\hline Range & $45.00-61.00$ & $33.00-70.00$ & $33.00-70.00$ & \\
\hline
\end{tabular}

Note: ${ }^{*}$ Fisher's Exact test $\mathrm{p}<0,05{ }^{* *}$ Kolmogorov Smirnov test 
Table 2 Tumor Locations in Patients with Head and Neck Squamous Cell Carcinoma at Dr. Hasan Sadikin Hospital in 2019

\begin{tabular}{lcc}
\hline \multirow{2}{*}{ Tumor Locations } & \multicolumn{2}{c}{ Clinical Stage } \\
\cline { 2 - 3 } & Early Stage & Advanced Stage \\
\hline Oropharynx & 2 & 3 \\
Paranasal sinus & 1 & 3 \\
Nasopharynx & 0 & 2 \\
Larynx & 4 & 13 \\
\hline
\end{tabular}

Table 3 Comparison of HPV IgG Levels Based on Clinical Stage in Patients with Head and Neck Squamous Cell Carcinoma

\begin{tabular}{lccc}
\hline \multirow{2}{*}{ Variable } & Early Stage & Advanced Stage & p-value \\
\cline { 2 - 3 } & I-II $(\mathbf{n}=\mathbf{7})$ & III-IV $(\mathbf{n}=\mathbf{2 1})$ & $0.001^{* *}$ \\
\hline HPV IgG level & & & \\
Mean \pm SD & $2,344 \pm 1,255$ & $4,708 \pm 1,386$ & \\
Median & 2.100 & 4.900 & \\
Range & $998-4,350$ & $1,100-6,800$ & \\
\hline
\end{tabular}

Note: **Unpaired T-test, $\mathrm{p}<0.05$

pharynx, or larynx. About 90\% of head and neck cancers are squamous cell carcinomas. Cancers originates in the cells that line the mouth, nose, throat, ears, and also the surface of the tongue. ${ }^{1,8}$

Gender is a risk factor for head and neck cancer. HNSCC is more frequent in males than females, conform to the result in this study which showed that the male:female ratio of HNSCC patients was 2:1. This result is similar to a study in the Asia Pacific, which involved patients with HNSCC in various educational centers with a male:female ratio of 4:1.2 This might be related to exposure to cigarette smoke, alcohol, and carcinogenic. Moreover, patients with advanced stage are also mostly found in the male gender., ${ }^{2,9}$

Head and neck cancer is common in old age. Our initial search of medical records showed that of a total of 638 HNSCC patients, $51.9 \%$ were from the 51-60 year age category and $23.8 \%$ were $60-70$ years old. In our current study, patients $>50$ years were $75 \%$, confirming that the patients of HNSCC mostly were at an average age of 57 years. ${ }^{10}$ This is caused by a long process of carcinogenesis. Due to the carcinogenesis process from normal tissue needs a long time. The highest prevalence of HNSCC is among tobacco users, of whom $74 \%$ smoke $>10$ packs/year. ${ }^{5,10}$

According to the 2017 AJCC, HNSCC patients come at the advanced stage (III-IV) $75 \%$. The staging was designated based on the TNM scoring system namely tumor size, lymph nodes involvement, and metastasis. Only $25 \%$ of patients seek medical attention in the early stages (I-II). The main factors are difficulty in diagnosis, lack of symptoms, and lack of knowledge, besides the inadequate health facilities. The initial symptoms of head and neck tumors are typical, only resembling upper respiratory tract infections, stomatitis, voice changes, and nasal congestion. ${ }^{11}$

Human papillomavirus has been found in premalignant tumors and malignant tumors of the head and neck. Malignancy occurs due to HPV infection mediated by E6 and E7 proteins expression, inhibiting tumor suppressor gene pathways by inactivating TP53. ${ }^{12}$ The combined effect of the oncogeneous HVP, E6, E7, and E5 induces cell cycle progression in epithelial cells squamous oral cavity that is differentiated and growth suppressed, leading to carcinogenesis by proliferation deregulation, decreased apoptosis, genomic instability, and transformation processes. Measurement of several specific HPV16 antibodies in serum up to 15 years before the diagnosis of oropharyngeal cancer has shown a correlation between baseline HPV16 antibodies and antigens of E1, E2, E6, and E7 in oropharyngeal cancer. ${ }^{12,13}$

In this study, the value of the HPV IgG level in the clinical stage of HNSCC Stage I-II and Stage III-IV were 2.1 and 4.9, respectively, suggesting a significant relationship $(\mathrm{p}=0.000)$ between the variable HPV IgG levels and both.

HPV infection in squamous cell epithelium causes the formation of specific antibody antigens. The antibodies formed are specific IgG against HPV. ${ }^{14}$ Examination of HPV IgG antibodies in OPSCC patients in this study found that $95.6 \%$ had detectable IgG antibodies, which can be used as predictor of 
OPSCC risk. Specific HPV IgG antibodies serve as markers of squamous cell carcinogenesis and are important for strategies for the prevention or early detection of squamous cell carcinoma. ${ }^{7,15}$

The HPV serology was positively correlated with $86 \%$ of HNSCC patients who had been examined for HPV-DNA PCR and P16 IHC. The E7 antibody titer in serum was also positively correlated with p16 in HNSCC tissue, thus supporting the association between serological antibody and clinical stage with the incidence of HNSCC. ${ }^{10}$

Limitations in this study include the limited number of sample in the early-stages compared to the advanced stages. The HPV IgG examination has been detected by serum serology, measuring cumulative exposure of an individual to HPV infection. Thus, further research could be done to identify HNSCC caused by HPV using more sensitive and specific examination such as the combination of P16 immunohistochemistry and PCRHPVDNA.

In conclusion, there is a correlation between increased levels of HPV IgG and the clinical stage of HNSCC. Higher HPV IgG levels worsens the prognosis of HNSCC. Examination of HPV IgG levels can be used as a marker to assess the progression of HNSCC.

\section{References}

1. Agrawal GP, Joshi PS, Agrawal A. Role of HPV-16 in pathogenesis of oral epithelial dysplasia and oral Squamous cell carcinoma and correlation of p16INK4a expression in HPV-16 positive cases: an immunohistochemical study. ISRN Pathology.2013;2013:807095.

2. Yan W, Wistuba, II, Emmert-Buck MR, Erickson HS. Squamous cell carcinomasimilarities and differences among anatomical sites. Am J Cancer Res. 2011;1(3):275-300.

3. Syrjänen S. Human papillomaviruses in head and neck carcinomas. N Engl J Med. 2007;356(19):1993-5.

4. Sabirin MSM, Permana AD, Soeseno B. Epidemiologi penderita tumor ganas kepala leher di Departemen Telinga Hidung Tenggorokan-Kepala Leher Rumah Sakit Dr. Hasan Sadikin Bandung, Indonesia, periode 2010-2014. Tunas Medika Jurnal Kedokteran \& Kesehatan. 2016;3(1):269.

5. Kreimer AR, Johansson M, Waterboer T, Kaaks R, Chang-Claude J, Drogen D, et al. Evaluation of human papillomavirus antibodies and risk of subsequent head and neck cancer. J Clin Oncol. 2013;31(21):2708-15.

6. Cleary RK, Cmelak AJ. Human papillomavirus-positive oropharyngeal squamous cell carcinoma demographics, prognosis, and staging. Clin Oncol. 2016;1:1018.

7. Kerishnan JP, Gopinath SC, Kai SB, Tang T-H, Ng HL-C, Rahman ZAA, et al. Detection of human papillomavirus 16 -Specific IgG and IgM antibodies in patient sera: a potential indicator of oral squamous cell carcinoma risk factor. Int J Med Sci. 2016;13(6):42431.

8. Jiang R, Ekshyyan O, Moore-Medlin T, Rong X, Nathan S, Gu X, et al. Association between human papilloma virus/Epstein-Barr virus coinfection and oral carcinogenesis. J Oral Pathol Med. 2015;44(1):28-36.

9. Sathish N, Wang X, Yuan Y. Human papillomavirus (HPV)-associated oral cancers and treatment strategies. J Dent Res. 2014;93(7 Suppl):29S-36S

10. Khanal S, Joh J, Kwon AM, Zahin M, Perez CA, Dunlap NE, et al. Human papillomavirus E7 serology and association with p16 immunohistochemistry in squamous cell carcinoma of the head and neck. Exp Mol Pathol. 2015;99(2):335-40.

11. Rakhmawulan IA, Dewi YA, Nasution N. Profile of head and neck cancer patients at Department of OtorhinolaringologyHead and Neck Surgery Dr. Hasan Sadikin General Hospital Bandung. AMJ. 2015;2(4):474-9.

12. Liang C, Marsit CJ, McClean MD, Nelson HH, Christensen BC, Haddad RI, et al. Biomarkers of HPV in head and neck squamous cell carcinoma. Cancer Res. 2012;72(19):5004-13.

13. Anderson KS, Wallstrom G, Langseth $\mathrm{H}$, Posner M, Cheng JN, Alam R, et al. Pre-diagnostic dynamic HPV16 IgG seropositivity and risk of oropharyngeal cancer. Oral Oncol. 2017;73:132-7.

14. Dalianis T. Human papillomavirus and oropharyngeal cancer, the epidemics, and significance of additional clinical biomarkers for prediction of response to therapy (Review). Int J Oncol. 2014;44(6):1799-805.

15. Fakhry C, Qualliotine JR, Zhang Z, Agrawal N, Gaykalova DA, Bishop JA, et al. Serum antibodiestoHPV-16early proteinswarrant investigation as potential biomarkers for risk stratification and recurrence of HPVassociated oropharyngeal cancer. Cancer Prev Res (Phila). 2016;9(2):135-41. 